\title{
Endoscopic Vein Harvesting for Coronary Bypass Grafting: A Blessing or a Trojan Horse?
}

\author{
Ryan Accord and Jos Maessen \\ Department of Cardiothoracic Surgery, University Hospital Maastricht, P.Debyelaan 25, 6229 HX Maastricht, The Netherlands \\ Correspondence should be addressed to Ryan Accord, ryan.accord@gmail.com
}

Received 28 November 2010; Accepted 21 January 2011

Academic Editor: Hendrik T. Tevaearai

Copyright (๑) 2011 R. Accord and J. Maessen. This is an open access article distributed under the Creative Commons Attribution License, which permits unrestricted use, distribution, and reproduction in any medium, provided the original work is properly cited.

Conventional open harvest of the great saphenous vein (GSV) during CABG results in approximately 7\% donor-site complications. Using endoscopic vein harvesting (EVH) the full GSV length can be harvested through a $3 \mathrm{~cm}$ incision. This nonsystematic review discusses several key issues concerning EVH, based on an extensive Pubmed search. Found studies show that EVH results in reduced number of wound complications, less postoperative pain, earlier postoperative mobilisation, reduced length of hospital stay, and is more cost-effective. Initial studies did not find significant differences in graft histology, patency, or clinical outcome. However, in 2009 convincing evidence of inferior histological graft properties became available. Furthermore, an observational study showed that EVH resulted in significantly more graft stenosis, was associated with higher mortality, more myocard infarction, and more reinterventions. Most recent publications could not confirm these findings, however larger randomised controlled trials focusing on graft quality are being awaited.

\section{Introduction}

The great saphenous vein (GSV) is the most commonly used conduit for coronary artery bypass grafting (CABG). The referenced standard method of harvesting the GSV is by way of the open surgical technique. Depending on the required graft length, the average incision will vary between 20 and 40 centimetres. However, in the population of patients undergoing $\mathrm{CABG}$, risk factors for impaired wound healing are overrepresented. Evaluation of 1577 patients that underwent open GSV harvest for CABG in Maastricht, revealed that in $1.5 \%$ of patients donor-site infections were diagnosed before discharge [1]. Remarkably this figure increases to $4.6 \%$ at 30 days followup and $7.3 \%$ at 90 days followup. Therefore $80 \%$ of the donor-site infections are diagnosed after discharge, for instance by the patients general physician or cardiologist. Furthermore wound complications are often found to be responsible for additional surgery, prolonged hospital stay, increased hospital costs, and in some cases permanent disability $[1,2]$.
The introduction of endoscopic vein harvesting $(\mathrm{EVH})$ in 1996 seemed a welcome contribution to achieve goals set in modern cardiac surgery, namely, making cardiac surgery less invasive and promote earlier recovery after surgery. Now approximately 15 years after its introduction EVH has conquered an important place in standard clinical care (80\% of the CABG procedures conducted in the USA use EVH) [3]. Nevertheless, recent publications have raised doubts whether the quality and durability of an endoscopically harvested vein is comparable with a vein harvested in the traditional open fashion $[4,5]$. Is EVH indeed a blessing in the attempts to make cardiac surgery less invasive or do the recent publications reveal hidden dangers? This nonsystematic review article aims to give an overview of 15 years of clinical experience with $\mathrm{EVH}$, with appropriate attention for graft quality. Based on a Pubmed search all original papers, review articles, systematic reviews, and meta-analysis were collected. For the search several combinations of the terms endoscopic, minimal invasive, vessel, vein, conduit, harvest, and harvesting were used. Reports investigating 


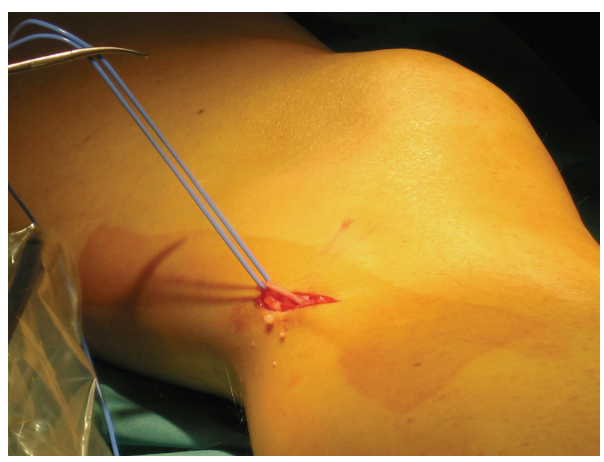

(a)

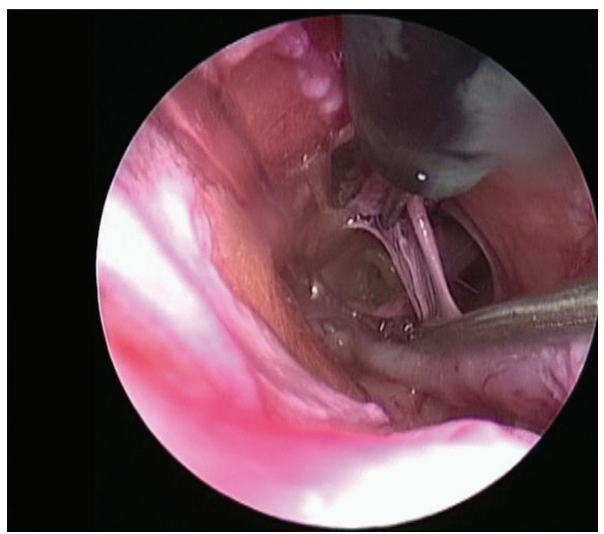

(c)

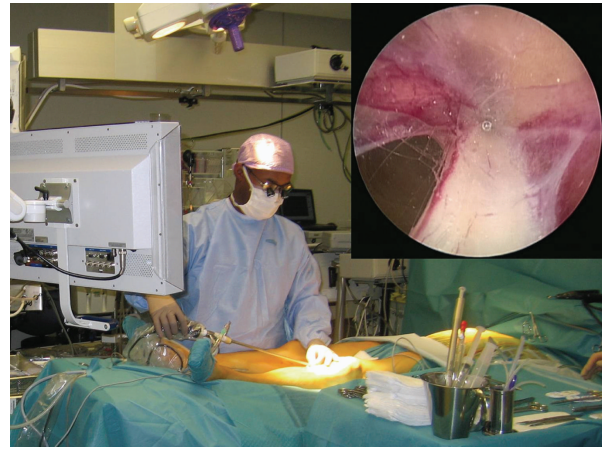

(b)

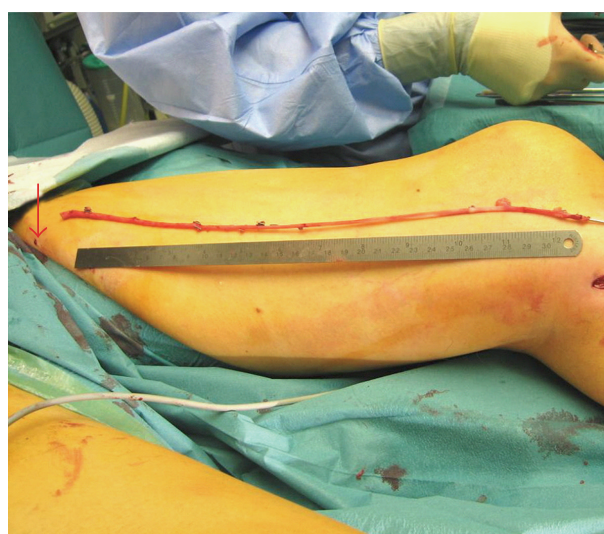

(d)

FIGURE 1: Endoscopic vein harvesting. (a) The first step is the identification of the great saphenous vein (GSV) through a 3-cm incision near the knee. (b) The next step is the dissection of the vein from the surrounding subcutaneous tissue. (c) After creating a tunnel by means of $\mathrm{CO}_{2}$ insufflation, all side branches of the GSV are identified, coagulated using diathermy and transected. (d) The final result is demonstrated, $35 \mathrm{~cm}$ of vein harvested through a $3 \mathrm{~cm}$ incision near the knee and a $3-\mathrm{mm}$ counterincision in the groin (arrow).

radial artery harvest, noncardiac use of vein conduits, the bridging technique, or other nonendoscopic techniques were excluded.

\section{Procedure, Learning Curve, and Safety}

2.1. The Procedure. During EVH disposable or reusable systems are used to harvest approximately $35 \mathrm{~cm}$ of the upper leg GSV through a $3 \mathrm{~cm}$ incision on the medial side of the knee (Figure 1). By repeating the same procedure in the other direction, the entire GSV $(70 \mathrm{~cm})$ can be harvested through a single incision. Several systems are available, most frequently used are the disposable systems, namely, Vasoview by Maquet, VirtuoSaph by Terumo, and Clearglide by Sorin.

2.2. Learning Curve. Even though EVH systems have become more user-friendly over the years, a significant personal as well as institutional learning curve persists. Analysis of 1348 patients undergoing $\mathrm{EVH}$ revealed that the average procedural time of the first 50 cases was 68 minutes, while the procedural time dropped significantly to 23 minutes in the last 200 cases [6]. In general one can expect a personal learning curve of 20-100 procedures, depending on surgical experience.
2.3. Safety. Based on the review of available literature, EVH can be considered a save operative procedure. The few case reports describing EVH specific complications relate to the use of $\mathrm{CO}_{2}$ insufflation, namely, severe hypercapnia, subclinical $\mathrm{CO}_{2}$ embolization $(10.4 \%)$, and massive $\mathrm{CO}_{2}$ embolization $(0.22 \%)$ [6, 7]. An important preventive measure is reduction of the $\mathrm{CO}_{2}$ insufflation pressure, most importantly not allowing the $\mathrm{CO}_{2}$ pressure to surpass the central venous pressure.

\section{Wound Healing Disturbances}

3.1. Noninfectious Healing Disturbances. The most complete overview article investigating noninfectious wound healing disturbances is by Athanasiou et al. [29]. This meta-analysis included 27 studies republished between 1995 and 2002, within total 4953 patients. Analysis of 12 randomised controlled trials showed a significant reduction of noninfectious wound healing disturbances (wound drainage, haematoma, oedema, dehiscence, necrosis, need for surgical debridement, and seroma formation) from $13 \%$ in open vein harvest to $4 \%$ after EVH. The number needed to treat in order to prevent one complication was only 2 for oedema and 13 for the other complications. 
Diabetes, hyperlipidemia, obesity, female gender, advanced age, and peripheral vascular disease are known risk factors for wound healing disturbances after open GSV harvest $[2,14]$. Research has however shown that particularly these high-risk patients benefit most from minimally invasive harvest techniques. For example, in patients with diabetes and obesity no additional risk of wound healing disturbances can be found anymore if EVH is used [14, 15].

3.2. Wound Infections. It is assumed that EVH reduces the number of donor-site infections because it causes less trauma to the surrounding tissue, preserves tissue perfusion, and is less likely to create vital tissue flaps [16]. A meta-analysis from 2003 included all available randomised controlled trials that investigated the incidence of donor-site infections (drainage of pus from the wound, positive wound cultures, and requirement for additional treatment surgical or antibiotic treatment) [16]. Eleven randomised controlled trials, with in total 1156 patients had used endoscopic techniques. All individual studies found reduced or at least equal infection rates after $\mathrm{EVH}$. This meta-analysis revealed that the overall wound infection rate dropped from $13 \%$ in the open harvest group to $3 \%$ in the EVH group.

\section{Postoperative Pain and Mobility}

Postoperative pain quantified using the visual analogue scale, is significantly reduced after EVH compared to the traditional open harvest method [17-20]. Coppoolse et al. demonstrated that patients undergoing EVH rate their experience of pain 2 points lower (on a $0-10$ scale) throughout the whole postoperative period and label themselves painfree days earlier than their counterparts that underwent open harvest [20]. It is therefore not surprising that a number of studies show that patients undergoing EVH are able to mobilize earlier and are also more mobile at hospital discharge and 6 weeks after surgery $[17,19,21]$.

\section{Hospital Length of Stay and Costs}

5.1. Hospital Length of Stay (LOS). With the reduction of wound complications and earlier mobilisation of patients, it is likely that recovery time and therefore LOS is reduced. Two independent studies have indeed showed reduction in LOS in patients undergoing EVH, respectively, 31 and 34\% reduction compared to traditional conduit harvest [21, 22]. Another study found a nonsignificant increase of LOS in the EVH group [23]. The remaining 7 available studies investigating this aspect of $\mathrm{EVH}$, found trends towards reduced LOS, without significant differences [17, 18, 24-28]. A metaanalysis from 2004 with in total 1757 patients confirmed a reduction of LOS if EVH is used [29].

5.2. Hospital Costs. In the Netherlands an average disposable-system costs $€ 400$ per procedure. So a legitimate question is whether the additional costs of EVH are justified by the potential benefits. A controlled trial compared the total hospital costs of 100 patients undergoing either EVH or conventional harvest and found no significant differences [30]. The reduction in costs by EVH that the authors had expected, was not found because of the longer use of the operating room on the one hand and failure to reduced LOS on the other. In 2008, a study became available which investigated cost-effectiveness [31]. Because data on healthrelated quality of life was lacking, postoperative pain and mobilisation was used as a measure of effectiveness. Procedural costs were calculated based on previous publications on LOS, operation-time, and prices of the most expensive EVH system. So it is important to note that costs of readmissions, outpatient visits related to wound problems and costs of wound treatments were not included in his model. Nevertheless, EVH was found to be the most costeffective method of vein harvest.

\section{Cosmetic Result and Quality of Life}

Since the scare after EVH is considerably smaller, it is not surprising that patients are significantly more satisfied with the cosmetic result after EVH then after the traditional harvest $[17,23]$. However this difference in appreciation, measured using a visual analog scale from $0-10$, is mostly notable during the first postoperative period. Six weeks after surgery the cosmetic outcome is equally appreciated [17]. Whatever the case may be, no improvement in quality of life, measured using a Short Form 36 questionnaire, has been demonstrated at 2 and 4 weeks after surgery [30].

\section{Graft Quality and Durability}

Suture repairs because of holes or torn side branches of the endoscopically harvested vein are 3-5 times more often necessary then after open vein harvest $[12,32]$. The presence of these macroscopic lesions make one presume that the endoscopic technique inflicts more trauma to the vessel then the conventional open harvest technique. Furthermore, concerns exist with regards to thermal spread due to diathermic coagulation of side branches, detrimental effects of $\mathrm{CO}_{2}$ insufflation, and formation of microscopic clots in the collapsed GSV due to the pressurized working tunnel. It has been suggested that this last concern can be dealt with by early systemic heparinization [33].

7.1. Histological Evaluation. Initial studies addressing graft histology did not find differences in injury to the vascular wall and found comparable endothelial integrity after EVH compared to open harvest $[17,19,27,34]$. One study even found superior endothelial integrity after EVH [35]. However, in 2009 Boston researchers showed evidence of injury to the saphenous vein endothelium during endoscopic harvest [4]. Using three independent techniques (immunohistochemistry, western blot, and multiphoton microscopy), they demonstrated reduced calcium mobilization, nitric oxide production, and esterase activity and reduced levels of von Willebrand factor, all signs of impaired structural and functional viability of saphenous vein endothelium. The authors state that the found detrimental effects on saphenous 
TABLE 1: Graft quality in terms of graft patency and clinical outcome.

\begin{tabular}{|c|c|c|c|c|c|c|}
\hline \multirow{2}{*}{ Authors, yr } & \multirow{2}{*}{ Method } & \multirow{2}{*}{$N$} & \multirow{2}{*}{ Followup } & \multicolumn{2}{|c|}{ Patency rate } & \multirow{2}{*}{ Clinical outcome (EVH versus open harvest) } \\
\hline & & & & $\%$ & $P$ value & \\
\hline $\begin{array}{l}\text { Felisky et al., } \\
2002[8]\end{array}$ & retrospective & $\begin{array}{l}380 \mathrm{EVH} \\
340 \mathrm{OVH}\end{array}$ & In-hospital & - & - & $\begin{array}{l}\text { no significant differences in rate of clinically apparent } \\
\text { early graft failure }\end{array}$ \\
\hline $\begin{array}{l}\text { Allen et al., } \\
2003 \text { [9] }\end{array}$ & RCT & $\begin{array}{l}54 \mathrm{EVH} \\
58 \mathrm{OVH}\end{array}$ & $5 \mathrm{yr}$ & - & - & $\begin{array}{l}\text { equal } 5 \text { yr event-free survival (events: death, AMI, } \\
\text { recurrent AP) }\end{array}$ \\
\hline $\begin{array}{l}\text { Perrault et al., } \\
2004[10]\end{array}$ & RCT, CAG & $\begin{array}{l}40 \mathrm{EVH} \\
40 \mathrm{OVH}\end{array}$ & $3 \mathrm{~m}$ & $\begin{array}{l}85 \% \\
84 \%\end{array}$ & .991 & - \\
\hline $\begin{array}{l}\text { Davis et al., } \\
2004[11]\end{array}$ & $\begin{array}{l}\text { retrospective, } \\
\text { CE-CT }\end{array}$ & $\begin{array}{l}51 \mathrm{EVH} \\
50 \mathrm{OVH}\end{array}$ & $\begin{array}{l}3.7 \mathrm{yr} \\
0.7 \mathrm{yr}\end{array}$ & $\begin{array}{l}95 \% \\
95 \%\end{array}$ & n.s. & - \\
\hline $\begin{array}{l}\text { Yun et al., } \\
2005[12]\end{array}$ & RCT, CAG & $\begin{array}{l}100 \mathrm{EVH} \\
100 \mathrm{OVH}\end{array}$ & $6 \mathrm{~m}$ & $\begin{array}{l}68 \% \\
70 \%\end{array}$ & .584 & - \\
\hline $\begin{array}{l}\text { Lopes et al., } \\
2009 \text { [5] }\end{array}$ & $\begin{array}{c}\text { prospective } \\
\text { nonrandomized, } \\
\text { CAG }\end{array}$ & $\begin{array}{l}1753 \mathrm{EVH} \\
1247 \mathrm{OVH}\end{array}$ & $3 \mathrm{yr}$ & $\begin{array}{l}73 \% \\
77 \%\end{array}$ & $<.001$ & $\begin{array}{l}\text { associated with higher rates of death, myocardial } \\
\text { infraction, or repeat revascularization }\end{array}$ \\
\hline $\begin{array}{l}\text { Ouzounian } \\
\text { et al., } 2010[3]\end{array}$ & $\begin{array}{l}\text { prospective } \\
\text { observational }\end{array}$ & $\begin{array}{l}2004 \mathrm{EVH} \\
3821 \mathrm{OVH}\end{array}$ & $2.6 \mathrm{yr}$ & - & - & $\begin{array}{l}\text { not an independent predictor of in-hospital or midterm } \\
\text { adverse outcome }\end{array}$ \\
\hline $\begin{array}{l}\text { Kirmani et al., } \\
2010[13]\end{array}$ & case-control & $\begin{array}{c}89 \mathrm{EVH} \\
182 \mathrm{OVH}\end{array}$ & $\begin{array}{l}17 \mathrm{~m} \\
38 \mathrm{~m}\end{array}$ & - & - & $\begin{array}{l}\text { no difference in the rates of freedom from angina, } \\
\text { readmission or need for further antianginals }\end{array}$ \\
\hline
\end{tabular}

ns: not significant; EVH: endoscopic vein harvesting, OVH: open vein harvesting, CAG: coronary angiogram, RCT: randomized controlled trial; AMI: acute myocardial infarction; AP: angina pectoris; CE-CT: contrast-enhanced CT.

vein endothelium may lead to decreased graft patency and worse patient outcome.

7.2. Graft Patency. Only a limited number of studies are available that give insights into angiographic implication of possible histological vein injury. Two randomised controlled trials were not able to show significant differences in patency rate between patient undergoing EVH or OVH $[10,12]$. In both studies followup was however short, namely, 3 and 6 months. Davis et al. on the other hand, compared patients who had undergone EVH 3.7 years prior, to patients that had undergone open harvest 0.7 years earlier [11]. Contrastenhanced CT showed good patency rate after EVH, which did not differ from the control group with the shorter followup.

7.3. Clinical Outcome. Studies that investigate clinical outcome after EVH (e.g., recurrent angina, number of reinterventions, recurrent acute myocardial infarction, and survival) are scarcely available. One retrospective study compared patients undergoing EVH with a historical control group [8]. No significant differences in clinically apparent graft failure could be noted. Allen et al. conducted an RCT with a fairly small number of patients (112 isolated CABG patients) and found comparable 5 years event-free survival between the EVH and open harvest group [9]. If a proper power analysis was conducted remains unclear, since no description is provided.

Several months after the Boston group published about inferior histological properties of endoscopically harvested vein an important clinical paper was published in the New England Journal of Medicine. Lopes et al. conducted a secondary analysis on 3000 patients that had been included in the PREVENT IV trial [5]. This phase 3 trial had investigated the effect of ex vivo treatment of saphenous vein conduits with Edifoligide and had not found any beneficial effect on graft patency. In 1753, study subjects the vein graft had been harvested endoscopically and in the remaining 1247 through open surgery. Comparing the two groups revealed that patients who underwent EVH had higher rates of vein graft failure at 12 to 18 months. At 3 years, EVH was associated with higher death $(7.4 \%$ versus $5.8 \%)$, myocardial infarction, or repeat revascularization. It is important to note that the harvest method was not randomly assigned and that details on harvest technique (e.g., used system, experience of the endoscopist, upper or lower leg harvest, and heparin administration) were missing.

A recent observational study compared 5825 patients of whom 34\% had undergone EVH [3]. At a followup of 2.6 years no correlation between harvest method and recurrent angina, number of reinterventions, acute coronary syndrome, heart failure or survival could be found. EVH was even associated with a reduced number of readmissions for unstable angina. The most recent publication on clinical outcome is a retrospective case control study [13]. This study was also not able to find differences in the rates of freedom from angina, readmission, need for further antianginals or overall survival. For an overview of the available clinical studies see Table 1.

\section{Conclusions}

The aim of minimally invasive conduit harvest techniques is to reduce the morbidity and recovery time associated with the procedure, whilst preserving the quality of the conduit [36]. A series of benefits are well founded adequately: $\mathrm{EVH}$ results in less wound healing disturbances, less donorsite infections, less postoperative pain, earlier postoperative mobilisation, reduced length of hospital stay, and is likely 
to be cost-effective. However, recent publications question whether the condition of preserved conduit quality is met. All currently available publication addressing graft quality have important shortcomings, including nonrandomised designs, nonstandardized harvest methods, small sample sizes, retrospective nature, or having only short-term followup. Since EVH has reached an advanced stage of implementation, and has become accepted and by patients highly appreciated by part of standard care, thorough randomised evaluation has become more difficult. Nevertheless a moral obligation exists to ensure without any doubt safety and durability of the endoscopically harvested conduit, since conduit quality is likely to influence clinical outcome of CABG, the golden standard for a considerable portion of patients with multivessel coronary artery disease. Therefore randomised controlled trials are necessary to settle this issue indefinitely. Aim of such a trial should be to show noninferiority of EVH versus open harvest. Since we now have reason to suspect clinical implications of possible inferior graft quality based on the findings of Lopes et al., the only relevant endpoint is MACE (Major Adverse Cardiac Events). The comparison with PCI versus CABG debate is in some part valid. The high number of covariates influencing in the primary endpoint will demand hundreds of study subjects in each study arm. The study of Lopes et al. also learned us that followup should be at least one year and that the most interesting secondary endpoint would be graft patency at one year. Obviously such a study would be costly, while in this field profit margins are considerably smaller then in the PCI industry. Willingness of companies to invest large amount of money in such studies will probably be less. Nevertheless a randomised controlled trial was initiated by a manufacturer of EVH systems, namely, the OPTION study. This study, that is, a single centre, 100 patient trial, investigating graft patency among other endpoint, one year after CABG surgery. Results of this and future initiatives will be eagerly awaited, since they will determine the future of endoscopic vein harvesting.

\section{Conflict of Interests}

The authors declare that there is no conflict of interests.

\section{References}

[1] D. Jonkers, T. Elenbaas, P. Terporten, F. Nieman, and E. Stobberingh, "Prevalence of 90-days postoperative wound infections after cardiac surgery," European Journal of CardioThoracic Surgery, vol. 23, no. 1, pp. 97-102, 2003.

[2] M. Abbaszadeh, M. K. Arabnia, A. Rabbani, M. H. Mandegar, and S. Vahedi, "The risk factors affecting the complications of saphenous vein graft harvesting In aortocoronary bypass surgery," Brazilian Journal of Cardiovascular Surgery, vol. 23, no. 3, pp. 317-322, 2008.

[3] M. Ouzounian, A. Hassan, K. J. Buth et al., "Impact of endoscopic versus open saphenous vein harvest techniques on outcomes after coronary artery bypass grafting," Annals of Thoracic Surgery, vol. 89, no. 2, pp. 403-408, 2010.

[4] L. J. Rousou, K. B. Taylor, X. G. Lu et al., "Saphenous vein conduits harvested by endoscopic technique exhibit structural and functional damage," Annals of Thoracic Surgery, vol. 87, no. 1, pp. 62-70, 2009.

[5] R. D. Lopes, G. E. Hafley, K. B. Allen et al., "Endoscopic versus open vein-graft harvesting in coronary-artery bypass surgery," New England Journal of Medicine, vol. 361, no. 3, pp. 235-244, 2009.

[6] K. M. Chiu, C. L. Chen, S. H. Chu, and T. Y. Lin, "Endoscopic harvest of saphenous vein: a lesson learned from 1,348 cases," Surgical Endoscopy and Other Interventional Techniques, vol. 22, no. 1, pp. 183-187, 2008.

[7] K. B. Leissner, A. Woo, R. Ortega, and G. D. Stanley, "Endoscopic saphenous vein harvest: severe hypercarbia," Journal of Cardiothoracic and Vascular Anesthesia, vol. 20, no. 5, pp. 759-760, 2006.

[8] C. D. Felisky, D. L. Paull, M. E. Hill et al., "Endoscopic greater saphenous vein harvesting reduces the morbidity of coronary artery bypass surgery," American Journal of Surgery, vol. 183, no. 5, pp. 576-579, 2002.

[9] K. B. Allen, D. A. Heimansohn, R. J. Robison, J. J. Schier, G. L. Griffith, and E. B. Fitzgerald, "Influence of endoscopic versus traditional saphenectomy on event-free survival: fiveyear follow-up of a prospective randomized trial," The heart surgery forum, vol. 6, no. 6, pp. E143-E145, 2003.

[10] L. P. Perrault, H. Jeanmart, L. Bilodeau et al., "Early quantitative coronary angiography of saphenous vein grafts for coronary artery bypass grafting harvested by means of open versus endoscopic saphenectomy: a prospective randomized trial," Journal of Thoracic and Cardiovascular Surgery, vol. 127, no. 5, pp. 1402-1407, 2004.

[11] Z. Davis, D. Garber, S. Clark et al., "Long-term patency of coronary grafts with endoscopically harvested saphenous veins determined by contrast-enhanced electron beam computed tomography," Journal of Thoracic and Cardiovascular Surgery, vol. 127, no. 3, pp. 823-828, 2004.

[12] K. L. Yun, Y. Wu, V. Aharonian et al., "Randomized trial of endoscopic versus open vein harvest for coronary artery bypass grafting: six-month patency rates," Journal of Thoracic and Cardiovascular Surgery, vol. 129, no. 3, pp. 496-503, 2005.

[13] B. H. Kirmani, J. B. Barnard, F. Mourad, N. Blakeman, K. Chetcuti, and J. Zacharias, "Mid-term outcomes for Endoscopic versus Open Vein Harvest: a case control study," Journal of Cardiothoracic Surgery, vol. 5, no. 1, article no. 44, 2010.

[14] K. B. Allen, D. A. Heimansohn, R. J. Robison et al., "Risk factors for leg wound complications following endoscopic versus traditional saphenous vein harvesting," The heart surgery forum, vol. 3, no. 4, pp. 325-330, 2000.

[15] G. Nasso, A. Anselmi, C. M. De Filippo et al., "Evaluation of less invasive method for saphenous vein harvest in patients with type II diabetes," Journal of Cardiovascular Medicine, vol. 8, no. 7, pp. 511-516, 2007.

[16] T. Athanasiou, O. Aziz, P. Skapinakis et al., "Leg wound infection after coronary artery bypass grafting: a metaanalysis comparing minimally invasive versus conventional vein harvesting," Annals of Thoracic Surgery, vol. 76, no. 6, pp. 2141-2146, 2003.

[17] B. Kiaii, B. C. Moon, D. Massel et al., "A prospective randomized trial of endoscopic versus conventional harvesting of the saphenous vein in coronary artery bypass surgery," Journal of Thoracic and Cardiovascular Surgery, vol. 123, no. 2, pp. 204-212, 2002.

[18] Z. Davis, H. K. Jacobs, M. Zhang, C. Thomas, and Y. Castellanos, "Endoscopic vein harvest for coronary artery bypass grafting: technique and outcomes," Journal of Thoracic and Cardiovascular Surgery, vol. 116, no. 2, pp. 228-235, 1998. 
[19] P. Bonde, A. N. J. Graham, and S. W. MacGowan, "Endoscopic vein harvest: advantages and limitations," Annals of Thoracic Surgery, vol. 77, no. 6, pp. 2076-2082, 2004.

[20] R. Coppoolse, W. Rees, R. Krech, M. Hufnagel, K. Seufert, and $\mathrm{H}$. Warnecke, "Routine minimal invasive vein harvesting reduces postoperative morbidity in cardiac bypass procedures. Clinical report of 1400 patients," European Journal of CardioThoracic Surgery, vol. 16, no. 2, pp. S61-S66, 1999.

[21] A. N. Patel, R. F. Hebeler, B. L. Hamman et al., "Prospective analysis of endoscopic vein harvesting," American Journal of Surgery, vol. 182, no. 6, pp. 716-719, 2001.

[22] J. Y. Li, S. S. Wang, F. Y. Lin, C. H. Tsai, and S. H. Chu, "Video-assisted endoscopic saphenous vein harvesting for coronary artery bypass grafting," Journal of the Formosan Medical Association, vol. 97, no. 12, pp. 819-825, 1998.

[23] U. P. Schurr, M. L. Lachat, O. Reuthebuch et al., "Endoscopic saphenous vein harvesting for CABG - a randomized, prospective trial," Thoracic and Cardiovascular Surgeon, vol. 50, no. 3, pp. 160-163, 2002.

[24] K. B. Allen, G. L. Griffith, D. A. Heimansohn et al., "Endoscopic versus traditional saphenous vein harvesting: a prospective, randomized trial," Annals of Thoracic Surgery, vol. 66, no. 1, pp. 26-32, 1998.

[25] T. Z. Hayward, L. A. Hey, L. L. Newman et al., "Endoscopic versus open saphenous vein harvest: the effect on postoperative outcomes," Annals of Thoracic Surgery, vol. 68, no. 6, pp. 2107-2111, 1999.

[26] G. F. Galbraith and W. Pica-Furey, "A retrospective comparative study of open and endoscopic saphenous vein harvesting," Journal of Endovascular Therapy, vol. 7, no. 6, pp. 460-468, 2000.

[27] J. D. Crouch, D. P. O’Hair, J. P. Keuler, T. P. Barragry, P. H. Werner, and L. H. Kleinman, "Open versus endoscopic saphenous vein harvesting: wound complications and vein quality," Annals of Thoracic Surgery, vol. 68, no. 4, pp. 15131516, 1999.

[28] J. J. Andreasen, V. Nekrasas, and C. Dethlefsen, "Endoscopic vs open saphenous vein harvest for coronary artery bypass grafting: a prospective randomized trial," European Journal of Cardio-Thoracic Surgery, vol. 34, no. 2, pp. 384-389, 2008.

[29] T. Athanasiou, O. Aziz, S. Al-Ruzzeh et al., "Are wound healing disturbances and length of hospital stay reduced with minimally invasive vein harvest? A meta-analysis," European Journal of Cardio-Thoracic Surgery, vol. 26, no. 5, pp. 10151026, 2004.

[30] J. D. Puskas, C. E. Wright, P. K. Miller et al., "A randomized trial of endoscopic versus open saphenous vein harvest in coronary bypass surgery," Annals of Thoracic Surgery, vol. 68, no. 4, pp. 1509-1512, 1999.

[31] C. Rao, O. Aziz, S. Deeba et al., "Is minimally invasive harvesting of the great saphenous vein for coronary artery bypass surgery a cost-effective technique?" Journal of Thoracic and Cardiovascular Surgery, vol. 135, no. 4, pp. 809-815, 2008.

[32] K. R. Vaidyanathan, M. N. Sankar, and K. M. Cherian, "Endoscopic vs conventional vein harvesting: a prospective analysis," Asian Cardiovascular and Thoracic Annals, vol. 16, no. 2, pp. 134-138, 2008.

[33] E. N. Brown, Z. N. Kon, R. Tran et al., "Strategies to reduce intraluminal clot formation in endoscopically harvested saphenous veins," Journal of Thoracic and Cardiovascular Surgery, vol. 134, no. 5, pp. 1259-1265, 2007.

[34] S. J. Alrawi, F. Balaya, R. Raju, J. N. Cunningham, and A. J. Acinapura, "A comparative study of endothelial cell injury during open and endoscopic saphenectomy: an electron microscopic evaluation," Heart Surgery Forum, vol. 4, no. 2, pp. 120-127, 2001.

[35] P. Lamm, G. Juchem, S. Milz, and B. Reichart, "Continuous graft perfusion: optimizing the quality of saphenous vein grafts," The Heart Surgery Forum, vol. 5, supplement 4, pp. S355-S361, 2002.

[36] O. Aziz, T. Athanasiou, and A. Darzi, "Minimally invasive conduit harvesting: a systematic review," European Journal of Cardio-Thoracic Surgery, vol. 29, no. 3, pp. 324-333, 2006. 


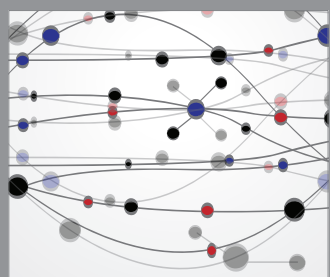

The Scientific World Journal
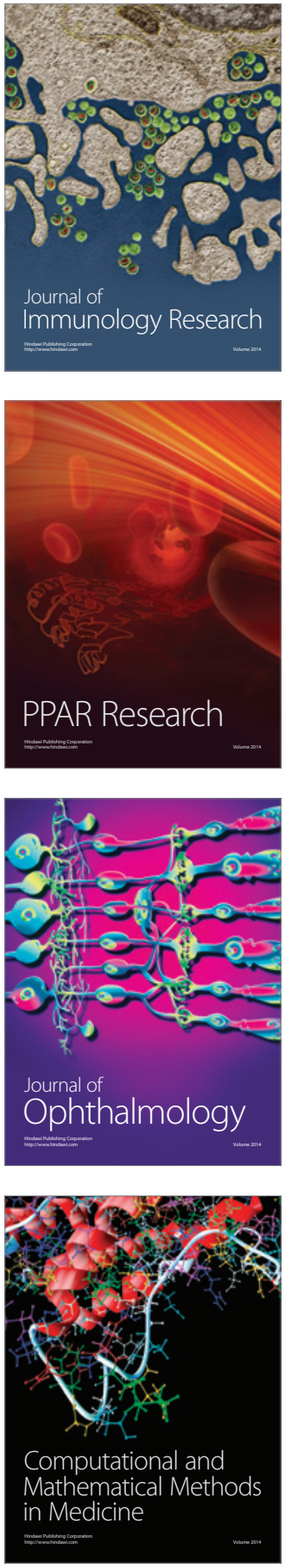

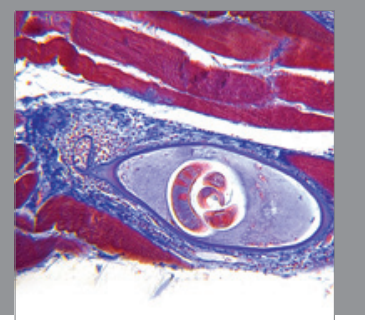

Gastroenterology

Research and Practice
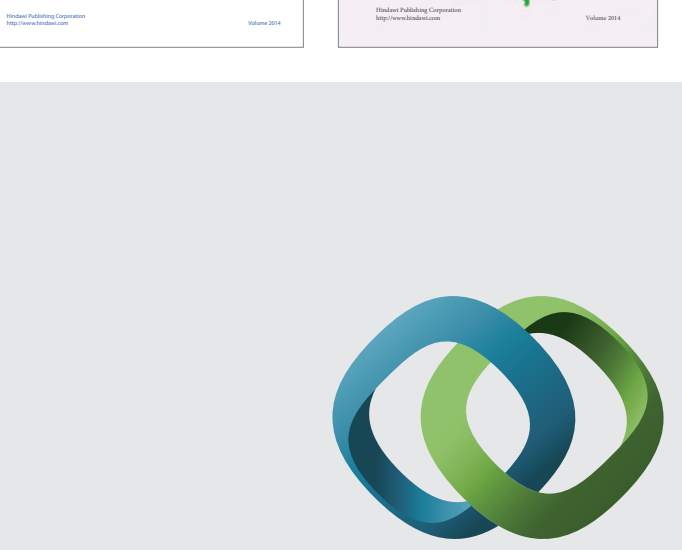

\section{Hindawi}

Submit your manuscripts at

http://www.hindawi.com
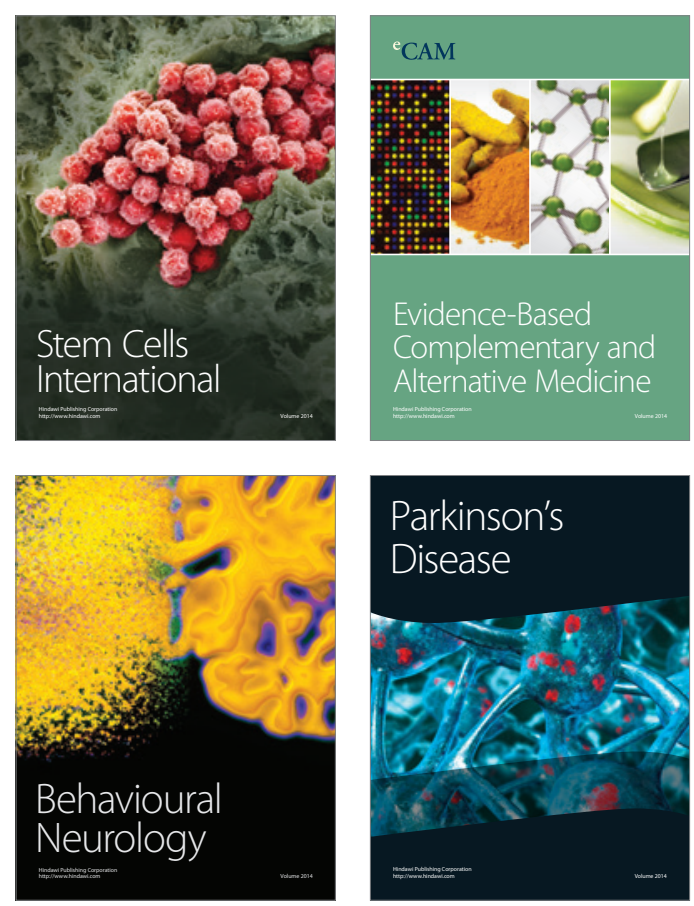

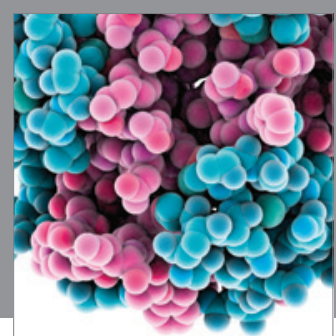

Journal of
Diabetes Research

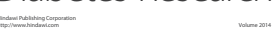

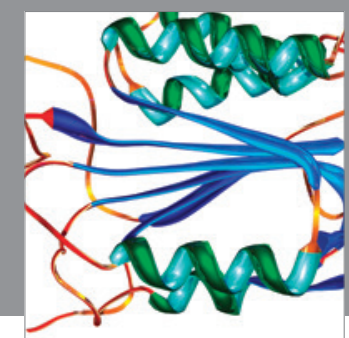

Disease Markers
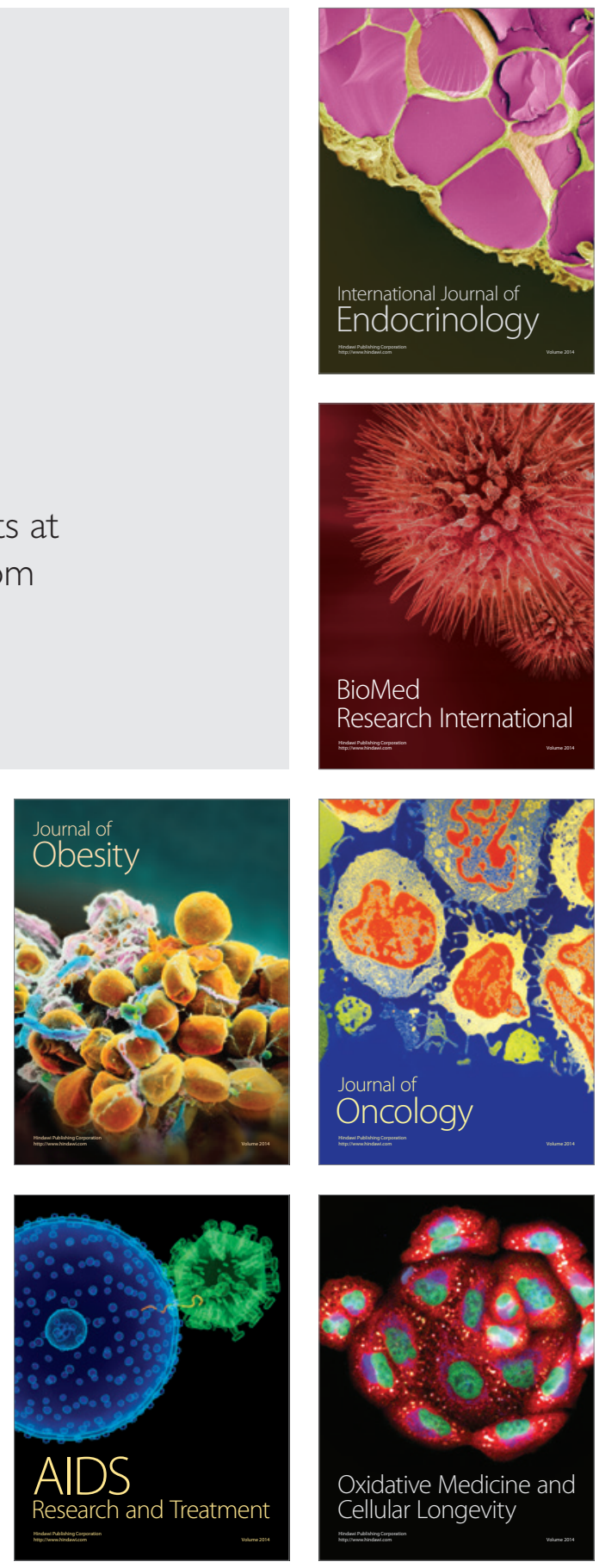